\title{
Kaiso is highly expressed in TNBC tissues of women of African ancestry compared to Caucasian women
}

\author{
Blessing I. Bassey-Archibong ${ }^{1} \cdot$ Shawn M. Hercules ${ }^{1} \cdot$ Lyndsay G. A. Rayner $^{1}$ \\ Desiree H. A. Skeete ${ }^{2,3} \cdot$ Suzanne P. Smith Connell ${ }^{3,4}$ - Ian Brain ${ }^{5}$. \\ Adetola Daramola $^{6}$ - Adekunbiola A. F. Banjo ${ }^{6}$ Jung S. Byun ${ }^{7} \cdot$ Kevin Gardner $^{7}$. \\ Jonathan Dushoff $^{1} \cdot$ Juliet M. Daniel $^{1}$
}

Received: 25 February 2017/ Accepted: 31 August 2017/Published online: 8 September 2017

(C) The Author(s) 2017. This article is an open access publication

\begin{abstract}
Purpose Triple-negative breast cancer (TNBC) is most prevalent in young women of African ancestry (WAA) compared to women of other ethnicities. Recent studies found a correlation between high expression of the transcription factor Kaiso, TNBC aggressiveness, and ethnicity. However, little is known about Kaiso expression and localization patterns in TNBC tissues of WAA. Herein, we analyze Kaiso expression patterns in TNBC tissues of African (Nigerian), Caribbean (Barbados), African American (AA), and Caucasian American (CA) women.

Methods Formalin-fixed and paraffin embedded (FFPE) TNBC tissue blocks from Nigeria and Barbados were utilized to construct a Nigerian/Barbadian tissue microarray
\end{abstract}

Electronic supplementary material The online version of this article (doi:10.1007/s10552-017-0955-2) contains supplementary material, which is available to authorized users.

Juliet M. Daniel

danielj@mcmaster.ca

1 Department of Biology, McMaster University, Hamilton, ON, Canada

2 Department of Pathology, Queen Elizabeth Hospital (QEH), Bridgetown, Barbados

3 Faculty of Medical Sciences, The University of the West Indies, Cave Hill Campus, Bridgetown, Barbados

4 Department of Radiation Oncology, Queen Elizabeth Hospital (QEH), Bridgetown, Barbados

5 Department of Pathology and Molecular Medicine, McMaster University, Hamilton, ON, Canada

6 Department of Anatomic and Molecular Pathology, Lagos University Teaching Hospital (LUTH), Lagos, Nigeria

7 Genetics Branch, National Institute of Health, Bethesda, MD, USA
(NB-TMA). This NB-TMA and a commercially available TMA comprising AA and CA TNBC tissues (AA-CAYTMA) were subjected to immunohistochemistry to assess Kaiso expression and subcellular localization patterns, and correlate Kaiso expression with TNBC clinical features. Results Nigerian and Barbadian women in our study were diagnosed with TNBC at a younger age than AA and CA women. Nuclear and cytoplasmic Kaiso expression was observed in all tissues analyzed. Analysis of Kaiso expression in the NB-TMA and AA-CA-YTMA revealed that nuclear Kaiso $\mathrm{H}$ scores were significantly higher in Nigerian, Barbadian, and AA women compared with CA women. However, there was no statistically significant difference in nuclear Kaiso expression between Nigerian versus Barbadian women, or Barbadian versus AA women. Conclusions High levels of nuclear Kaiso expression were detected in patients with a higher degree of African heritage compared to their Caucasian counterparts, suggesting a role for Kaiso in TNBC racial disparity.

Keywords Kaiso - TNBC - Women of African ancestry · Breast cancer racial disparity

\section{Introduction}

Breast cancer $(\mathrm{BCa})$ is a complex disease that occurs mostly in females and is a leading cause of female deaths worldwide [1-3]. The triple-negative breast cancer (TNBC) subtype accounts for a disproportionate number of $\mathrm{BCa}$ deaths due to its highly aggressive nature and metastatic tendencies [4-6]. As the name implies, triple-negative tumors represent a subset of breast tumors that are negative for the estrogen receptor (ER), progesterone receptor (PR), and human epidermal growth factor 
receptor-2 (HER2) [7]. Most TNBC are classified as basallike cancers and are generally characterized by high histologic/nuclear grade, increased rate of recurrence, and a greater frequency of epidermal growth factor receptor (EGFR) amplification, p53 mutations, and breast cancer type 1 (BRCA1) mutations [7, 8]. Due to their triple-negative status for ER, PR, and HER2, TNBCs lack targetedtreatment options, and cannot be treated with hormonal (Tamoxifen) or anti-HER2 therapies [7].

There is increasing evidence that TNBC occurs more frequently in young premenopausal African and AA women compared to Caucasian women [7, 9-14]. For example, Stark and colleagues reported that among Ghanaian BCa cases, there was a TNBC prevalence of $\sim 82 \%$ compared to the USA where TNBC prevalence was $\sim 33 \%$ and $\sim 10 \%$ among AA and CA cases, respectively [11]. Similarly, Agboola et al. reported a high incidence of TNBC among BCa cases in Nigerian women ( 48\%) compared with British women ( 14\%) [14]. The trend of high TNBC prevalence in AA and African females strongly suggests an ancestral genetic predisposition to TNBC in women of African ancestry (WAA) [15-17]. More disturbing, however, is the poor survival rate of AA TNBC patients compared with Caucasian TNBC patients [10, 18], which underscores the urgency to identify potential prognostic or diagnostic TNBC biomarkers in WAA.

Recent studies have found a correlation between increased nuclear expression of the transcription factor Kaiso and poor overall survival of AA breast cancer and prostate cancer patients compared to their Caucasian counterparts $[19,20]$. These data hint at a role for Kaiso in the racial disparity in outcomes associated with breast and prostate cancer. Kaiso was first identified as a binding partner of the E-cadherin catenin cofactor-p120-catenin [21]. Kaiso is a dual-specificity transcription factor and member of the POZ-ZF family of transcription factors [21-25] that are implicated in vertebrate development and tumorigenesis. Kaiso has been most often characterized as a transcriptional repressor [26], but some studies indicate that Kaiso can also function as a transcriptional activator [27, 28]. Notably, several Kaiso target genes identified to date (cyclinD1, matrilysin, E-cadherin) have been linked to tumor onset, invasion, and metastasis [29-31].

Since its discovery, Kaiso has been implicated in the poor prognostic outcomes of several cancers including colorectal, non-small cell lung cancer, prostate, pancreatic ductal adenocarcinoma, and TNBC [20, 32-35]. Studies from our lab and others indicates that Kaiso plays both prooncogenic and tumor suppressive roles in several human cancers $[19,20,33,34,36-38]$. Notably, in addition to being implicated in racial disparities in breast cancer outcomes, high Kaiso expression correlates significantly with ER- $\alpha$ negativity, and the aggressiveness of basal/TNBCs
[35, 38]. To date however, no studies have specifically examined and compared Kaiso expression and subcellular localization in TNBC tissues from WAA, who have the highest prevalence and worst outcomes from TNBC compared to Caucasian women. In this retrospective study, we evaluated Kaiso expression in TNBC specimens from Nigerian, Barbadian, AA, and CA patients. We found that nuclear Kaiso expression was significantly increased in TNBC tissues of Nigerian, Barbadian, and AA patients compared with their Caucasian counterparts. While there was no significant difference in nuclear Kaiso expression in TNBC tissues of Nigerian versus Barbadian patients (who have a higher percentage of African ancestry compared to AA), we found significantly more nuclear Kaiso expression in Nigerian versus AA patients, and a trend towards higher nuclear Kaiso expression in Barbadian versus AA patients. Collectively, these findings suggest that Kaiso may play a role in the racial disparity associated with TNBC in WAA.

\section{Methods}

\section{Study population and characteristics of tumor samples}

FFPE TNBC tissue blocks of 28 Nigerian TNBC patients diagnosed between 2011 and 2013 at the Lagos University Teaching Hospital (LUTH), Nigeria, and 46 Barbadian TNBC patients diagnosed between 2002 and 2011 at the Queen Elizabeth Hospital (QEH), Barbados were obtained from the archives of the Department of Anatomic and Molecular Pathology at LUTH and the Department of Pathology at QEH after approval by LUTH and QEH Ethics committees, respectively. The FFPE specimens were then shipped to the Developmental Histology Lab at the Yale Pathological Tissue Services (YPTS), Yale University (Connecticut, New Haven, USA), where they were hematoxylin and eosin (H\&E) stained for histopathological confirmation, before tumor areas from each FFPE tissue block were selected for the construction of a Nigerian and Barbadian TNBC tissue microarray (NBTMA). ER, PR, and HER2 status of the Nigerian tissues were confirmed by immunohistochemistry (IHC) conducted at LUTH, while ER, PR, and HER2 status of the Barbadian tissues were confirmed by IHC conducted at QEH, Barbados, the Human Tissue Resource Center (Chicago, IL, USA) or the Immunohistochemistry Lab at the University of Miami, Miller School of Medicine (Clinical Research Building, Miami, FL, USA). Any sample with less than $1 \%$ staining for ER and PR was scored negative; likewise, 0 or +1 for HER 2 was considered negative. Available clinico-pathological data (age, tumor pathology, lymph node involvement, and grade) 
were retrieved from the hardcopy pathology reports at LUTH and QEH, and are summarized in Table 1.

For the AA and CA patient population, we utilized the Yale tissue microarray 347 (YTMA-347), which was generated at the Yale Developmental Histology Lab, and comprised of $20 \mathrm{AA}$ and $43 \mathrm{CA}$ usable TNBC specimens that were diagnosed at the Yale-New Haven Hospital, Connecticut, USA between 1996 and 2004. ER, PR, and HER2 status were determined by IHC at the Yale Developmental Histology Lab. The clinico-pathological features of the YTMA-347 cohort are summarized in Table 1.

\section{Immunohistochemistry}

5- $\mu \mathrm{m}$ tissue sections prepared from the NB-TMA tissue block and the purchased YTMA-347 tissue slides were deparaffinized by warming at $60{ }^{\circ} \mathrm{C}$ for $20 \mathrm{~min}$, followed by immersion in xylenes for $10 \mathrm{~min}$. Tissue sections were then rehydrated in descending ethanol dilutions before they were subjected to heat antigen retrieval in a low $\mathrm{pH}$ buffer (pH 6.0) solution (DAKO, Glostrup, Denmark). Endogenous biotin, biotin receptors, and avidin binding sites on tissues were subsequently blocked using the Avidin/Biotin blocking kit (Vector Laboratories, Inc., Burlingame, CA, USA), while endogenous peroxidase activity was quenched by treatment with $3 \%$ hydrogen peroxide. Tissue slides were stained with mouse anti-Kaiso 6F monoclonal $(1: 10,000 ;[39])$ or mouse anti-human cytokeratin clones
AE1/AE3 monoclonal (1:500; Dako North America, Inc., Carpinteria, CA, USA) primary antibodies overnight at $4{ }^{\circ} \mathrm{C}$, followed by secondary antibody incubations at room temperature for $2 \mathrm{~h}$ with biotinylated donkey anti-mouse secondary antibody (Vector Labs; 1:1000). Tissues were subsequently incubated in Vectastain (Vector Labs) for $30 \mathrm{~min}$, rinsed in $1 \mathrm{X} \mathrm{PBS}$, and then incubated in diaminobenzidine (DAB) (Vector Labs) for $10 \mathrm{~min}$. Counterstaining was achieved by incubating tissues in Harris hematoxylin (Sigma) for 10-60 s, followed by rinsing in tap water or as described in [40]. Slides were then dehydrated in ascending alcohol dilutions, and cleared with two rounds of xylenes before being mounted using Polymount (Polysciences Inc., Warrington, PA, USA). Negative control staining data were achieved by slide incubation with secondary antibodies only. Images of stained slides were captured using the Aperio Slide scanner (Leica Biosystems, ON, Canada). Stained tissues were scored blindly by two Pathologists, and the scores averaged to give a final score value. The intensity of staining was scored as $0,1,2$, or 3 representing no, mild, moderate, or high staining intensity. The modified histochemical score (H-score) system was then used to generate the total score for each tissue with values spanning 0-300 using the formula: $3 \times$ (percentage of cells with high intensity staining $(3+)+2 \times$ (percentage of cells with moderate intensity staining $(2+)+1 \times$ (percentage of cells with mild intensity staining $(1+)$ for each slide.

Table 1 Clinico-pathological characteristics and analysis of study participants

\begin{tabular}{|c|c|c|c|c|c|c|}
\hline & $\begin{array}{l}\text { Nigerian }(\%) \\
n=28\end{array}$ & $\begin{array}{l}\text { Barbadian }(\%) \\
n=46\end{array}$ & $\begin{array}{l}\text { African American }(\%) \\
n=20\end{array}$ & $\begin{array}{l}\text { Caucasian American }(\%) \\
n=43\end{array}$ & $\begin{array}{l}\chi^{2} \\
\text { value }\end{array}$ & $p$ value \\
\hline \multicolumn{7}{|l|}{ Age (years) } \\
\hline$\leq 50$ & $20(71.4 \%)$ & $21(45.7 \%)$ & $6(30.0 \%)$ & $10(23.3 \%)$ & 16.89 & 0.0007 \\
\hline$>50$ & $5(17.9 \%)$ & $25(54.3 \%)$ & $7(35.0 \%)$ & $27(62.8 \%)$ & & \\
\hline Unknown $^{\mathrm{a}}$ & $3(10.7 \%)$ & $0(0.0 \%)$ & $7(35.0 \%)$ & $6(13.9 \%)$ & & \\
\hline \multicolumn{7}{|l|}{ Grade } \\
\hline 1 & $5(17.9 \%)$ & $0(0.0 \%)$ & $2(10.0 \%)$ & $13(30.2 \%)$ & 63.59 & $<0.0001$ \\
\hline 2 & $8(28.6 \%)$ & $9(19.6 \%)$ & $11(55.0 \%)$ & $21(48.9 \%)$ & & \\
\hline 3 & $10(35.7 \%)$ & $35(76.1 \%)$ & $0(0.0 \%)$ & $1(2.3 \%)$ & & \\
\hline Unknown $^{\mathrm{a}}$ & $5(17.8 \%)$ & $2(4.3 \%)$ & $7(35.0 \%)$ & $8(18.6 \%)$ & & \\
\hline \multicolumn{7}{|l|}{ Stage $T$} \\
\hline $\mathrm{T} 1-\mathrm{T} 2$ & $6(21.4 \%)$ & $18(39.1 \%)$ & $7(35.0 \%)$ & $23(53.5 \%)$ & 30.52 & $<0.0001$ \\
\hline T3-T4 & $11(39.3 \%)$ & $1(2.2 \%)$ & $1(5.0 \%)$ & $0(0.0 \%)$ & & \\
\hline Unknown $^{\mathrm{a}}$ & $11(39.3 \%)$ & $27(58.7 \%)$ & $12(60.0 \%)$ & $20(46.5 \%)$ & & \\
\hline \multicolumn{7}{|l|}{ Stage N } \\
\hline No & $4(14.3 \%)$ & $11(23.9 \%)$ & $7(35.0 \%)$ & $26(60.5 \%)$ & 10.23 & 0.02 \\
\hline N1-N3 & $11(39.3 \%)$ & $10(21.7 \%)$ & $13(65.0 \%)$ & $12(27.9 \%)$ & & \\
\hline Unknown $^{\mathrm{a}}$ & $13(46.4 \%)$ & $25(54.4 \%)$ & $0(0.0 \%)$ & $5(11.6 \%)$ & & \\
\hline
\end{tabular}

${ }^{\mathrm{a}}$ Unknown cases were exempted from analysis 
Fig. 1 Nigerian women are diagnosed with TNBC at younger ages than Barbadian, AA, and CA women. a The mean age at diagnosis for Nigerian TNBC patients was 42.6 years $(n=25)$ compared with 52.1 years for Barbadian women $(n=46), 51.5$ years for AA women $(n=13)$, and 56.2 years for CA women $(n=37)$. No significant differences were observed between the mean age at diagnosis for Barbadian versus $\mathrm{AA}$ and $\mathrm{CA}$ TNBC patients (b) and for AA versus CA patients (c). ${ }^{*} p<0.05$, ** $p<0.005, \quad{ }^{* * * *} p<0.0001$
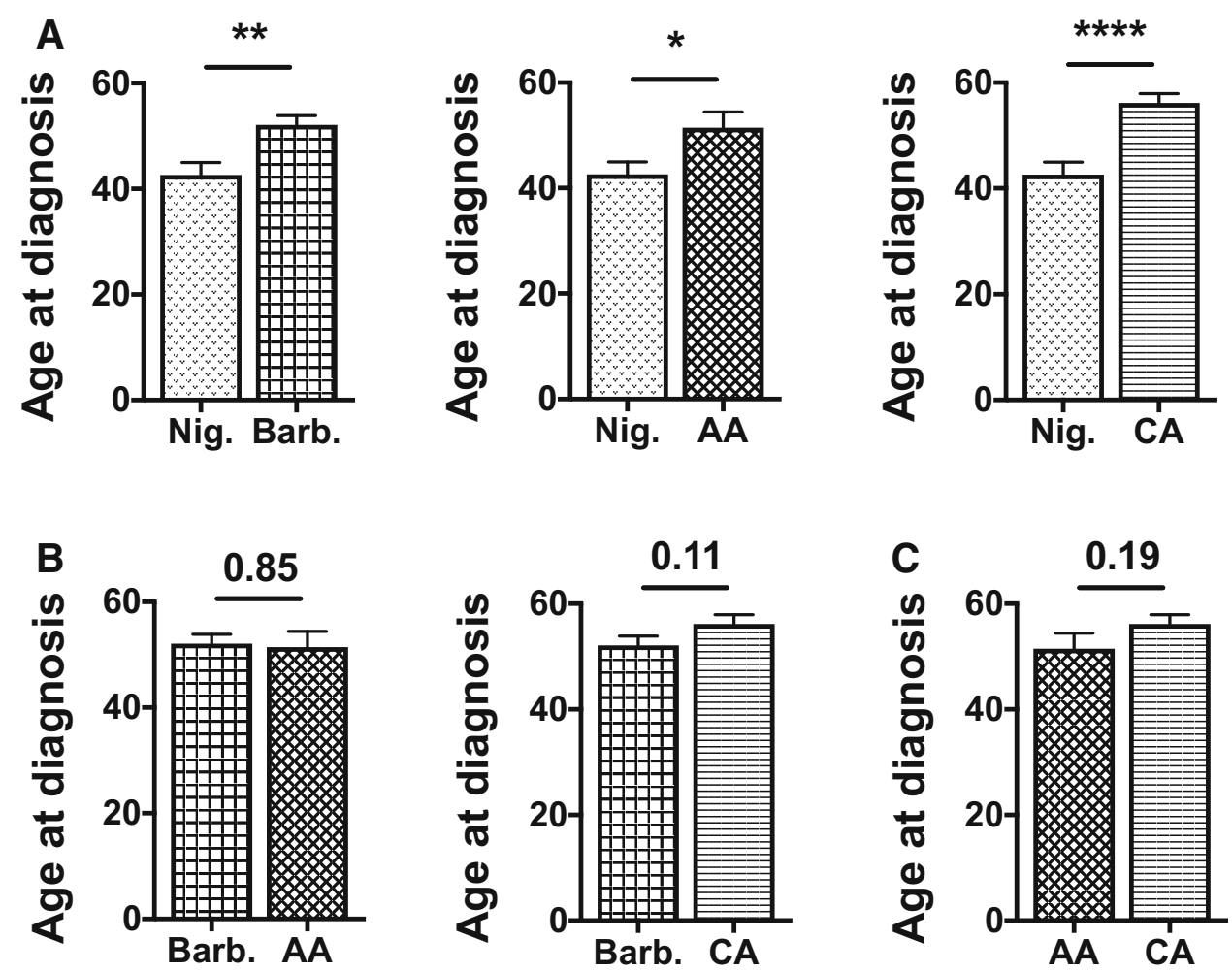

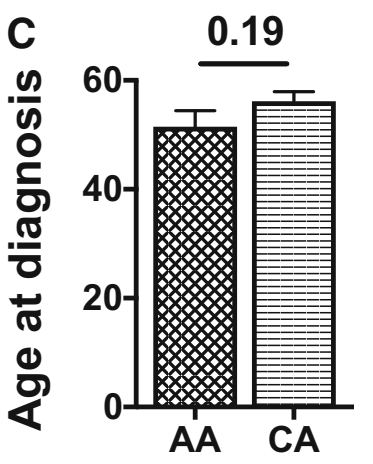

\section{Statistical analysis}

GraphPad Prism statistical software (GraphPad Software Inc., La Jolla, CA, USA) was used for all statistical analyses. Standard unpaired Student's $t$ test with Welch's correction was used for pairwise comparison of means. Chi square analysis was used to assess the difference in clinicopathological features between the Nigerian, Barbadian, $\mathrm{AA}$, and CA cohorts. Data are presented as mean \pm SEM where applicable. For all statistical tests, $p$ values $<0.05$ denote statistical significance.

\section{Results}

\section{Clinico-pathological characteristics of study participants}

This retrospective study involved a total of 28 Nigerian, 46 Barbadian, 20 African American (AA), and 43 Caucasian American (CA) TNBC patients. The mean age at time of diagnosis for Nigerian women was 42.6 years compared to 52.1 years for Barbadian women $(p=0.002), 51.5$ years for AA women $(p=0.03)$, and 56.2 years for CA women $(p<0.0001$; Fig. 1a). Comparison of the mean age at diagnosis between Barbadian, AA, and CA patients yielded no statistical significance (Fig. 1b, c). The percentage of younger women who presented with TNBC at time of diagnosis was significantly higher for the Nigerian cohort (71.4\%; $n=20)$ compared with the Barbadian (45.7\%; $n=21)$, AA $(30.0 \% ; n=6)$, and CA $(23.3 \% ; n=10)$ cohort $(p<0.001)$ (Table 1). Low-grade tumors were seldom observed in the Nigerian $(17.9 \% ; n=5)$, Barbadian $(0 \% ; n=0)$, and AA $(10.0 \% ; n=2)$ cohorts compared to the CA $(30.2 \% ; n=13)$ cohort $(p<0.0001$; Table 1). Low-grade was defined as grade 1 , mediumgrade as grade 2, and high-grade as grade 3, respectively. Approximately $39.3 \%(n=11)$ of Nigerian women presented with higher stage (T3-T4) tumors compared with $2.2 \%(n=1)$ for Barbadian, $5.0 \%(n=1)$ for AA, and $0 \%$ $(n=0)$ for CA women $(p<0.0001$; Table 1). Finally, CA TNBC patients displayed a higher frequency of lymph node-negative tumors $(60.5 \% ; n=26)$ compared with that observed in Nigerian $(14.3 \% ; n=4)$, Barbadian (23.9\%; $n=11)$, and AA $(35.0 \% ; n=7)$ TNBC patients $(p=0.02$; Table 1$)$.

\section{Kaiso is highly expressed in TNBC tissues of WAA compared to Caucasian women}

Previously, we reported that Kaiso is highly expressed at the mRNA level in triple-negative tumors compared with 
Fig. 2 Cytokeratin immunostaining of Nigerian and Barbadian TNBC tissues verifies tissue integrity. IHC images at low $(5 \times)$ and high magnification $(40 \times)$ show intact tissue cores $(\mathbf{a}, \mathbf{b})$ and membrane localization (ai, bi) of cytokeratin, which portrays good integrity of the Nigerian and Barbadian tissues. Scale bar $50 \mu \mathrm{m}$

\section{Pan-cytokeratin}

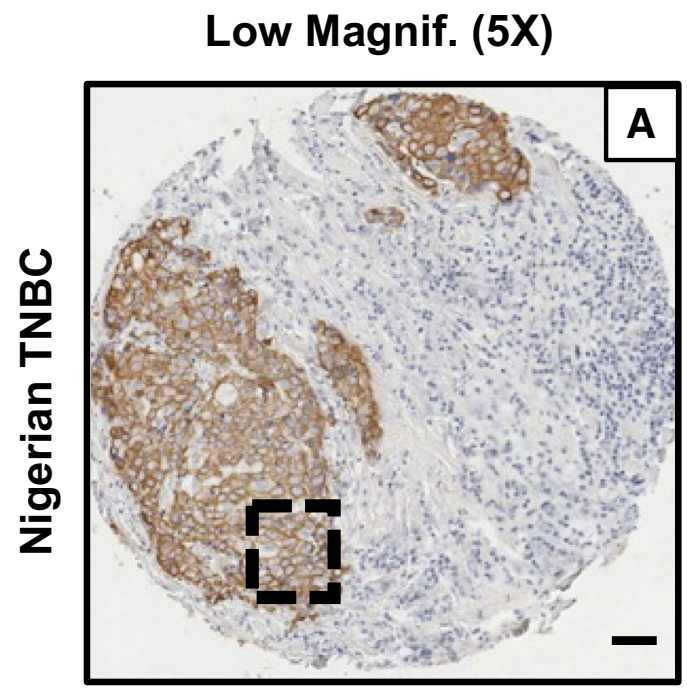

High Magnif. (40X)
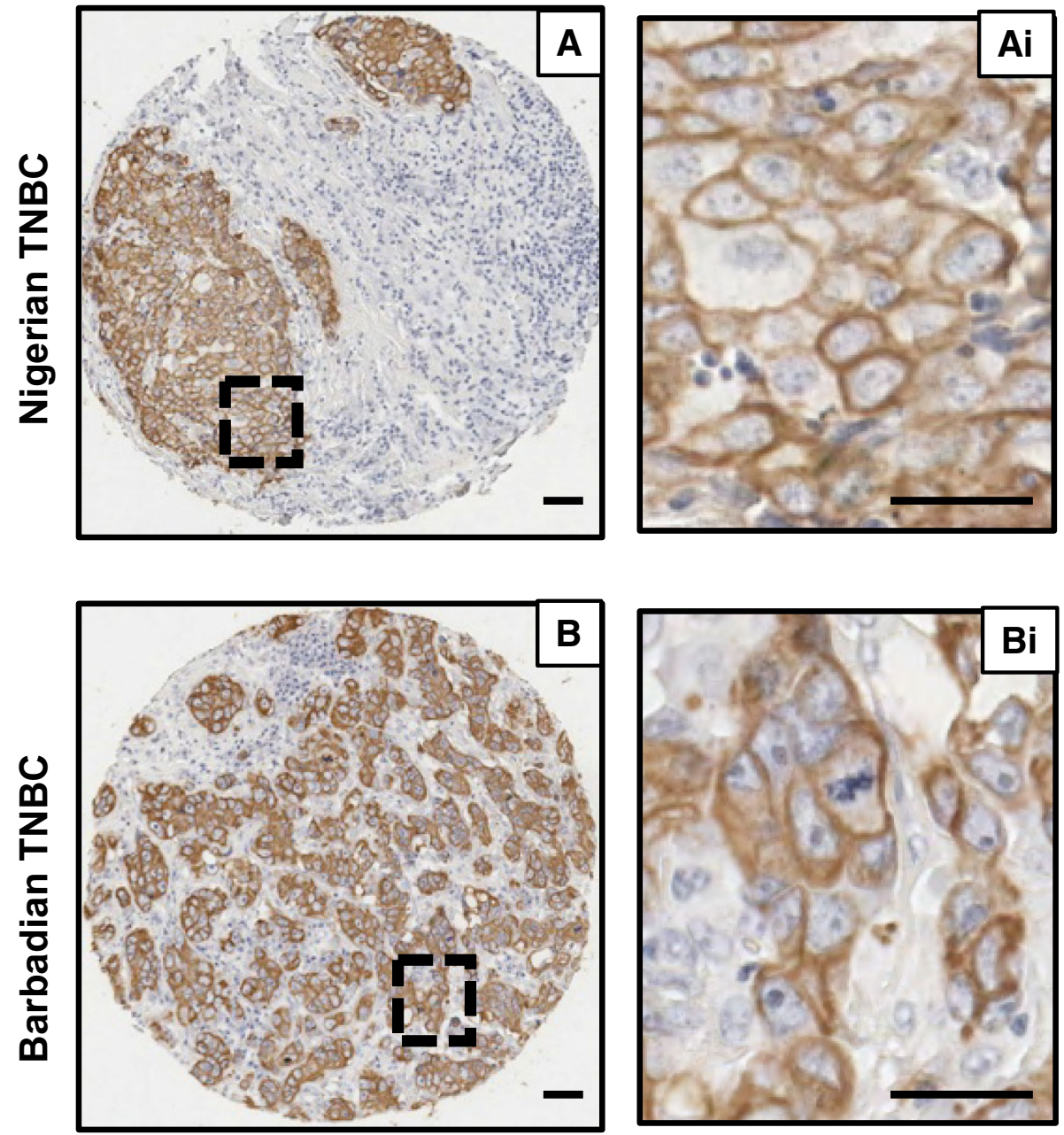

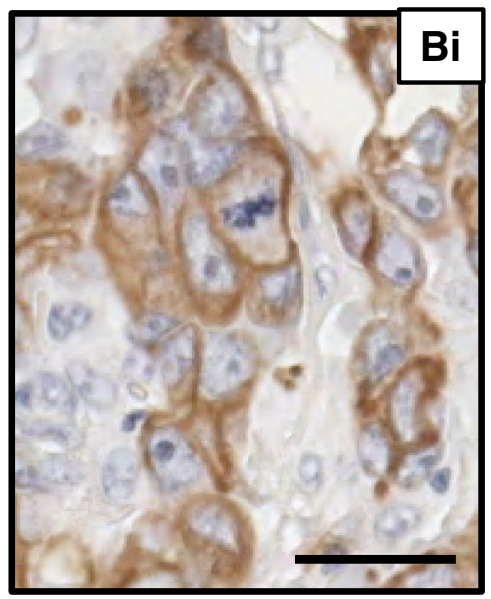

hormone receptor-positive breast tumors in publicly available datasets downloaded from The Cancer Genome Atlas-TCGA website or the Gene Expression OmnibusGEO website [35]. Thus, in this study, we utilized immunohistochemistry to specifically evaluate the expression and subcellular localization of Kaiso in TNBC tissues from Nigerian, Barbadian, AA, and CA patients. Tissue integrity of the Nigerian and Barbadian TNBC tissues was determined by immunostaining for pan-cytokeratin as described in the methods; Fig. 2a, b shows representative images of the tissue quality of the Nigerian and Barbadian TNBC tissues. As shown in Fig. 3a (representative images shown), Kaiso exhibited both nuclear and cytoplasmic localization in all TNBC tissues analyzed, with varying degrees of heterogeneity. Nuclear and cytoplasmic Kaiso staining intensity was scored as described in the methods, and Kaiso's relative expression in each TNBC cohort analyzed. As seen in Fig. 3b, we observed significantly higher cytoplasmic than nuclear Kaiso expression in the $\mathrm{AA}$ and CA TNBC cohorts $(p<0.0001)$, but did not find significant differences between nuclear and cytoplasmic Kaiso expression in the Nigerian and Barbadian TNBC cohorts.

Since nuclear but not cytoplasmic Kaiso expression is known to be associated with TNBC aggressiveness, and decreased survival of AA BCa patients [19, 38], we next performed comparative analysis of nuclear Kaiso expression between the Nigerian, Barbadian, AA, and CA cohorts. Interestingly, we observed a significantly higher level of nuclear Kaiso expression in TNBC tissues of patients of African ancestry (Nigerian, Barbadian, and AA) compared to their Caucasian counterparts (Fig. 4a). However, there was no significant difference between nuclear Kaiso expression in TNBC tissues of Nigerian and 
Fig. 3 Kaiso subcellular localization and expression in Nigerian, Barbadian, AA, and CA TNBC tissues. (ai-viii) IHC images showing Kaiso localization to both the nucleus and cytoplasm of Nigerian, Barbadian, AA, and CA TNBC tissues. (b) Graphical representation of nuclear and cytoplasmic Kaiso expression in Nigerian $(n=19)$, Barbadian $(n=20)$, AA $(n=20)$, and CA $(n=39)$ TNBC tissues.

Cytoplasmic Kaiso expression was significantly higher than nuclear Kaiso expression in the $\mathrm{AA}$ and CA TNBC cohorts but not in the Nigerian and

Barbadian TNBC cohorts. Red arrows indicate nuclear Kaiso staining, while blue arrows indicate cytoplasmic Kaiso staining. Scale bar $50 \mu \mathrm{m}$. $n s$ not significant, ${ }^{* * * *} p<0.0001$
A

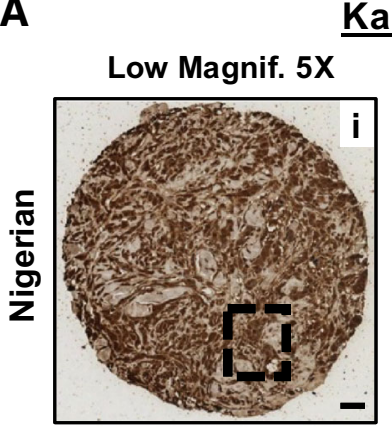

Kaiso
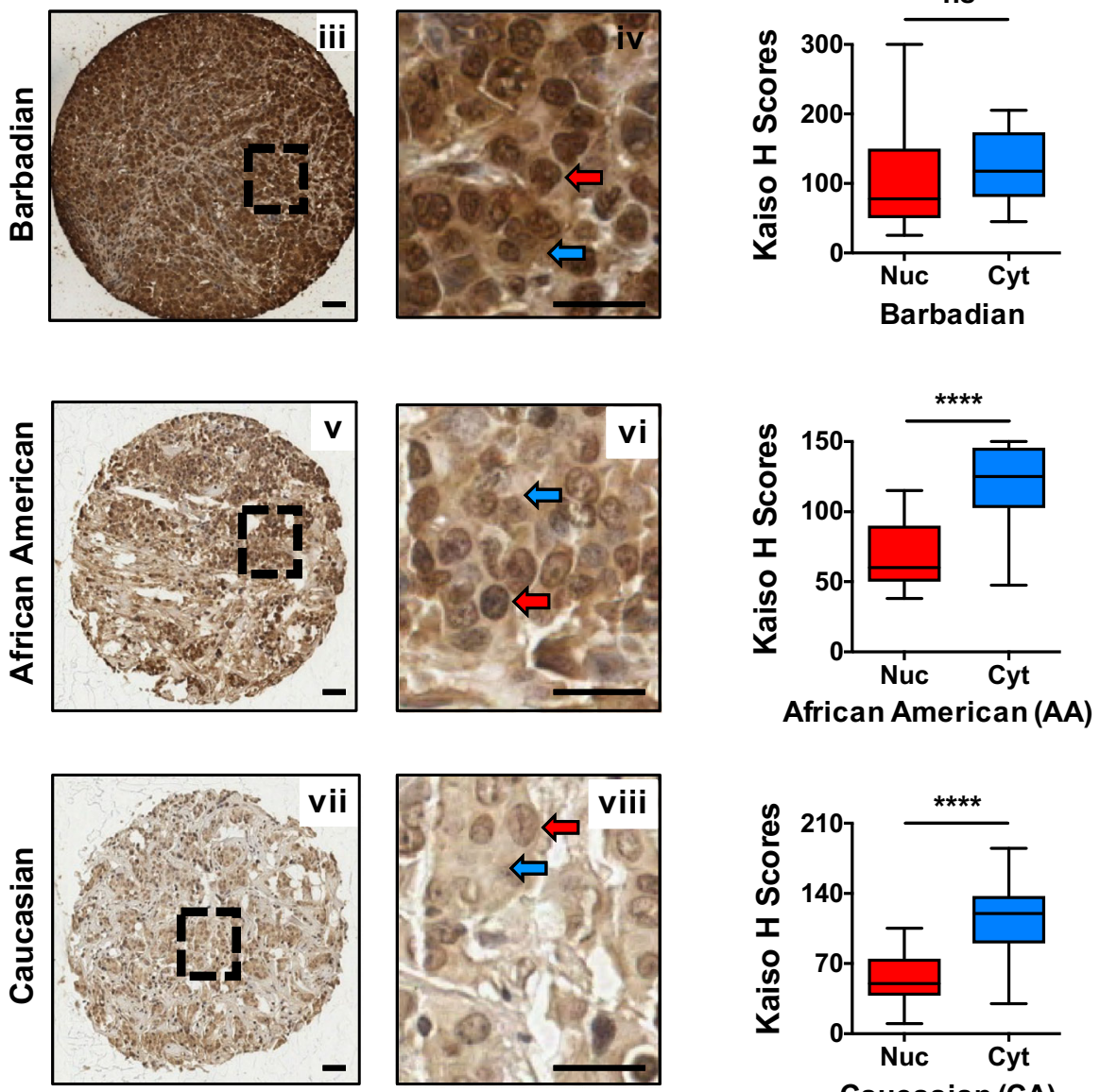

High Magnif. 40X
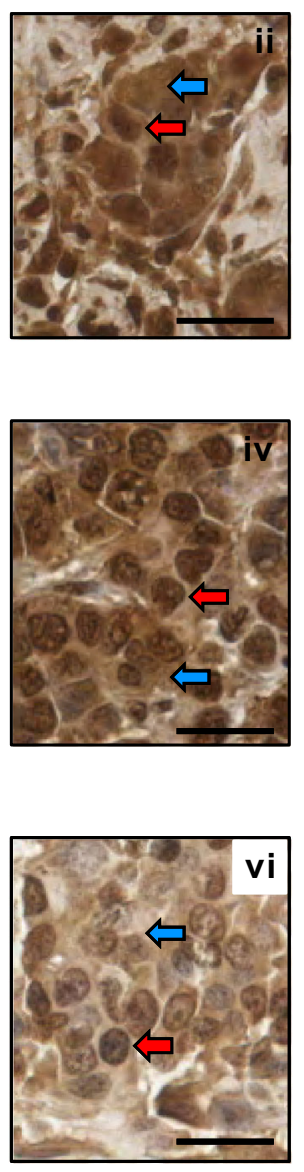

B
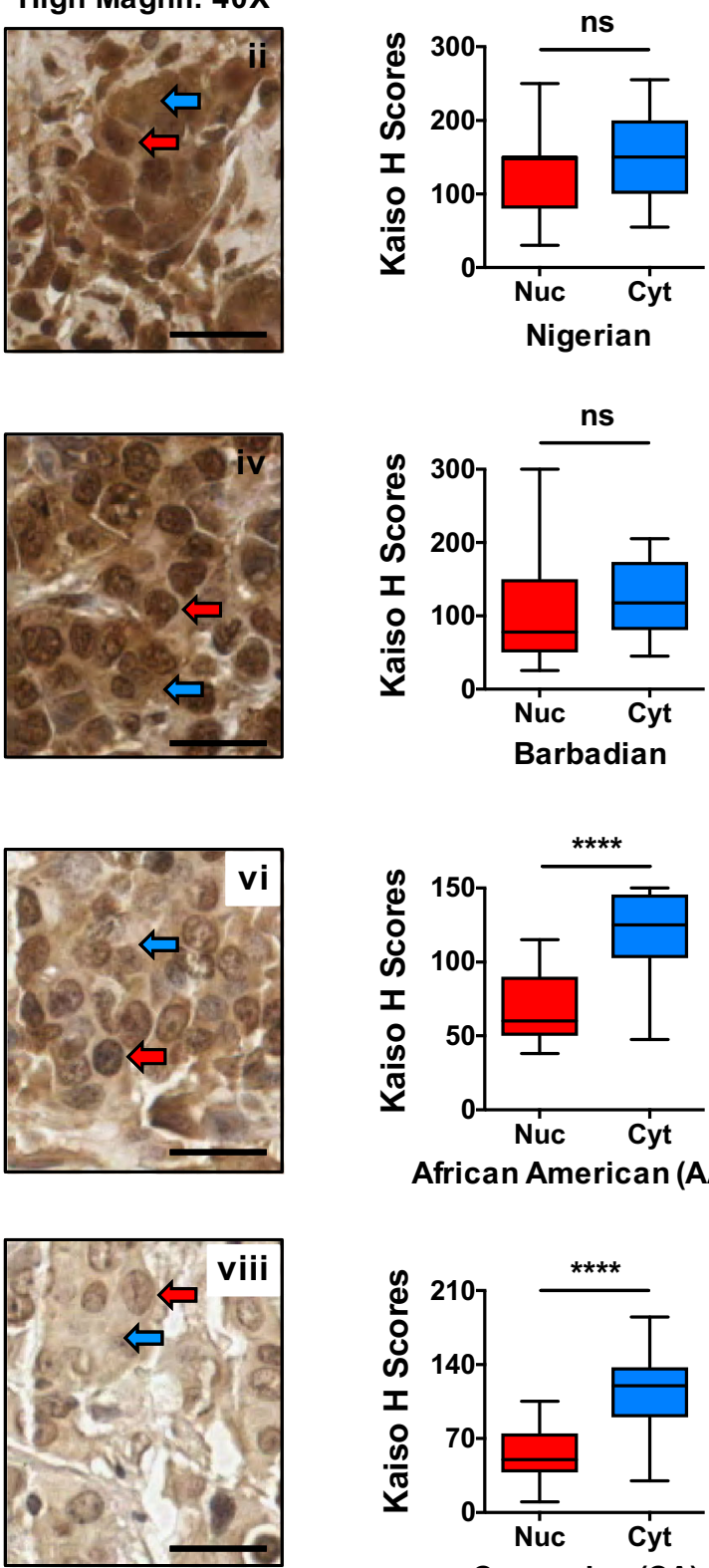

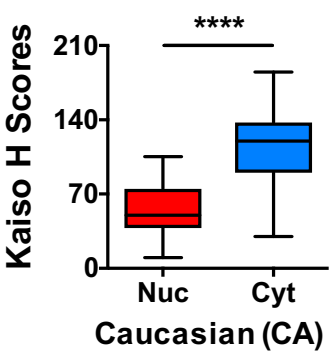

Barbadian patients, who have $\sim 99.8$ and $\sim 77.4 \%$ degree of African heritage, respectively [41, 42], or between TNBC tissues of Barbadian and AA patients, who have $\sim 77.4$ and $\sim 72.5 \%$ degree of African heritage, respectively [42] (Fig. 4b). Remarkably however, there was significantly more nuclear Kaiso expression in TNBC tissues of Nigerian compared to AA patients (Fig. 4c), probably due to the higher degree of African heritage in Nigerian patients $(\sim 99.8 \%)$ compared to AA patients $(\sim 72.5 \%)$. Since TNBC is more prevalent in WAA compared to Caucasian women, these findings suggest a role for nuclear
Kaiso expression levels in the racial disparity in TNBC prevalence.

\section{Correlation between nuclear Kaiso expression and clinico-pathological features of study participants}

Breast tumors of WAA are often associated with a higher histological grade and positive lymph node involvement compared to breast tumors of Caucasian women [11, 14]. Since previous studies from our lab and others have 

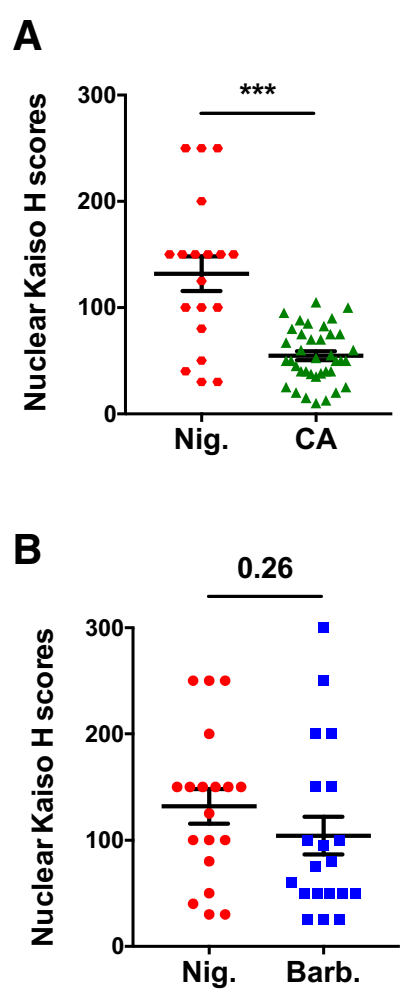
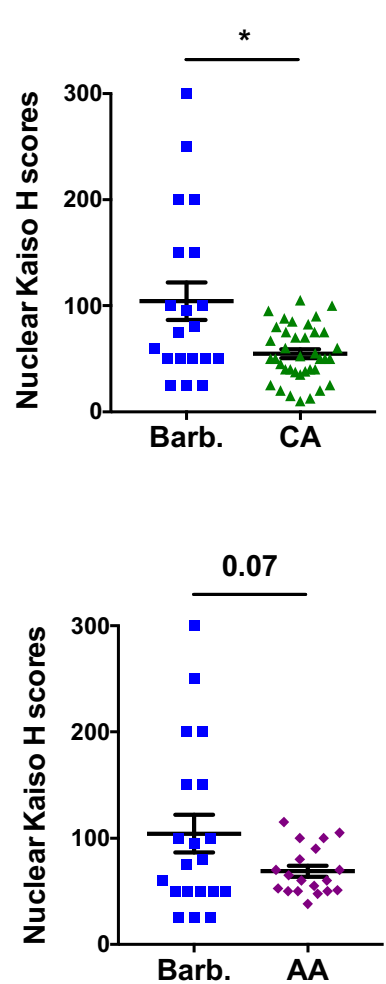

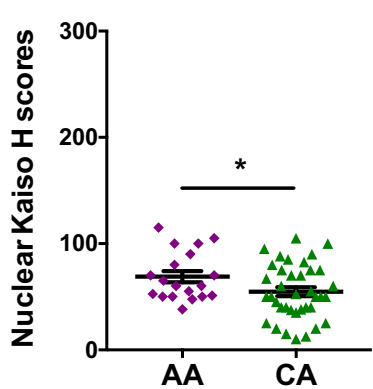

C

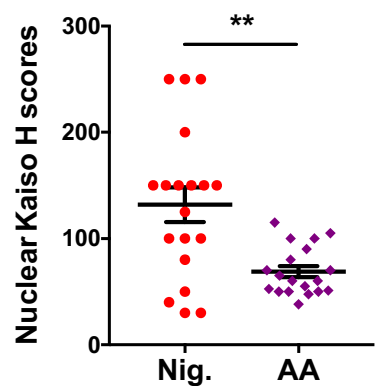

Fig. 4 Comparative analysis of nuclear Kaiso expression in Nigerian, Barbadian, AA, and CA TNBC tissues. Higher levels of nuclear Kaiso expression were detected in TNBC tissues of Nigerian, Barbadian, and AA compared with their Caucasian counterparts (a). Although no significant difference in nuclear Kaiso expression was observed between Nigerian versus Barbadian tissues, or between Barbadian versus AA tissues (b), there was a significant difference in nuclear Kaiso expression between Nigerian and AA TNBC tissues (c). ${ }^{*} p<0.05,{ }^{* *} p<0.005,{ }^{* * * *} p<0.001$ correlated increased Kaiso expression with advanced grade and metastasis of TNBC [35, 38], and lymph node involvement is an established prognostic marker for the metastatic potential of breast tumors [43], we next assessed the association of Kaiso expression with high-grade and lymph node involvement in Nigerian, Barbadian, AA, and CA patients. High-grade tumors were defined as grade 3 for Nigerian and Barbadian patients and grade 2 for AA and CA patients due to no analyzed grade 3 tumors in the AA and CA TNBC cohort (the only observed grade $3 \mathrm{CA}$ patient could not be scored as a result of tissue loss). Lowgrade tumors were thus defined as grades 1 and 2 for Nigerian and Barbadian patients, and grade 1 for AA and CA patients. Lymph node metastasis was considered positive if one or more lymph nodes were noted to contain cancer cells ( $\mathrm{n} 1-\mathrm{n} 3)$, and negative if there were no observed cancer cells in the lymph nodes (n0). Due to the small sample size used in the analysis, no significant correlation was found between high nuclear Kaiso expression and high-grade or lymph node-positive triple-negative tumors in any of the patient cohorts analyzed (Suppl. Figure 1).

\section{Discussion}

TNBC is most prevalent in WAA compared to Caucasian American/European females, but the reason for this disparity is currently unknown [11,14, 16, 44]. Although poor socio-economic status has been linked to TNBC mortality in African and AA women, it does not fully explain the disproportionate prevalence and aggressiveness of TNBC in WAA compared to their Caucasian counterparts [17]. Thus, we and others have postulated that there may be an ancestral genetic predisposition to TNBC in WAA [17, 45].

Notably, a higher prevalence of TNBC has been reported in West-African women (Nigerians-65\%, and Ghanaians-82.2\%) compared with that reported in AA$\sim 33 \%[9,11,46]$, thus supporting the idea of a relationship between percentage of African ancestry and TNBC prevalence. Since West-African countries such as Ghana and Nigeria are the founding ancestors of most WAA worldwide [41, 42, 47-49], we posit that there is a higher probability of identifying a founder mutation, if one exists, in Nigerian and Ghanaian populations, and also in more 
homogeneous populations of the African Diaspora such as the Caribbean (e.g., Barbados).

Recent studies have linked high nuclear expression of the transcription factor Kaiso with increased TNBC aggressiveness [20,38], and decreased survival of AA breast cancer patients compared with their Caucasian counterparts [19]. These reports suggest a link between increased nuclear Kaiso, TNBC aggressiveness/metastasis, and the racial disparity in prevalence/outcomes associated with breast cancer. Remarkably, our findings lend some credence to this hypothesis as we observed elevated expression of nuclear Kaiso in TNBC tissues from patients of African ancestry (Nigerians, Barbadians, and African Americans) compared to their Caucasian/European ancestry counterparts (CA) (see Fig. 4a). Thus, our previous findings in Kaiso-depleted mouse xenograft models $[35,51]$, where we demonstrated roles for Kaiso in TNBC cell growth, survival, and metastasis, may explain why high Kaiso-expressing triple-negative tumors in WAA are associated with a more aggressive phenotype and fatal outcomes than TNBC in Caucasian women.

Importantly, our findings highlight an interesting correlation between high nuclear Kaiso expression and percent African ancestry, which may be linked to the predisposition of young WAA to TNBC. However, this study is limited by the small sample size, the semi-quantitative method of analysis used, and lack of complete clinico-pathological information, which did not allow proper assessment of the correlation between Kaiso expression and the high tumor grade observed in African/Caribbean women compared to African American or Caucasian women. Additional studies using larger cohort sizes of West-African (Nigeria and others), Caribbean (Barbados and others), AA, and CA TNBC cases, coupled with quantitative methods of immunostain analysis such as the automated quantitative analysis (AQUA) system established by Rimm and colleagues [50], will undoubtedly provide more insight into the clinical relevance of nuclear Kaiso expression in the etiology of TNBC in WAA.

In conclusion, this is the first study to suggest a potential link between increased Kaiso expression and the predisposition of young WAA to TNBC. This observation, in addition to the previous identified roles for Kaiso in TNBC aggressiveness, metastasis, and poor overall survival in affected patients $[35,38,51]$, raises two exciting possibilities: i) Kaiso expression could be utilized as a biomarker for the diagnosis and prognosis of TNBC in WAA and ii) Kaiso could be a molecular target for the development of treatment options against TNBC not only in WAA but also TNBC patients worldwide.

Acknowledgments We would like to thank the staff and personnel of the Pathology and Oncology departments at QEH and LUTH, for their assistance with the samples used for this project. We would also like to thank Lori Charette and Dr. David Rimm (Department of Pathology, Yale University School of Medicine, New Haven, Connecticut, USA) for their assistance with the construction of the NigerianBarbadian TMA. This work was funded in part by the Canadian Breast Cancer Foundation ( $\mathrm{CBCF})$, the Juravinski Hospital and Cancer Center Foundation (JHCCF), and the Natural Sciences and Engineering Research Council of Canada (NSERC). BIB-A was partly supported by a Schlumberger Faculty for the Future Fellowship.

\section{Compliance with ethical standards}

Conflict of interest The authors declare that they have no conflict of interest.

Ethical approval All procedures performed in this retrospective study were in accordance with the ethical standards of LUTH and $\mathrm{QEH}$, respectively. For this type of study formal consent is not required.

Open Access This article is distributed under the terms of the Creative Commons Attribution 4.0 International License (http://crea tivecommons.org/licenses/by/4.0/), which permits unrestricted use, distribution, and reproduction in any medium, provided you give appropriate credit to the original author(s) and the source, provide a link to the Creative Commons license, and indicate if changes were made.

\section{References}

1. Hortobagyi GN, de la Garza Salazar J, Pritchard K, Amadori D, Haidinger R, Hudis CA et al (2005) The global breast cancer burden: variations in epidemiology and survival. Clin Breast Cancer. 6(5):391-401

2. Jemal A, Bray F, Center MM, Ferlay J, Ward E, Forman D (2011) Global cancer statistics. CA Cancer J Clin 61(2):69-90

3. Ferlay J, Soerjomataram I, Ervik M, Dikshit R, Eser S, Mathers C et al (2013) GLOBOCAN 2012 v1.0, Cancer incidence and mortality worldwide: IARC CancerBase No. 11 [Internet]. International Agency for Research on Cancer, Lyon

4. Oakman C, Viale G, Di Leo A (2010) Management of triple negative breast cancer. Breast 19(5):312-321

5. Carey LA (2011) Directed therapy of subtypes of triple-negative breast cancer. Oncologist 16(Suppl 1):71-78

6. Andre F, Zielinski CC (2012) Optimal strategies for the treatment of metastatic triple-negative breast cancer with currently approved agents. Ann Oncol 23(Suppl 6):vi46-vi51

7. Foulkes WD, Smith IE, Reis-Filho JS (2010) Triple-negative breast cancer. N Engl J Med 363(20):1938-1948

8. Irshad S, Ellis P, Tutt A (2011) Molecular heterogeneity of triplenegative breast cancer and its clinical implications. Curr Opin Oncol 23(6):566-577

9. Carey LA, Perou CM, Livasy CA, Dressler LG, Cowan D, Conway K et al (2006) Race, breast cancer subtypes, and survival in the Carolina Breast Cancer Study. JAMA 295(21):2492-2502

10. Lund MJ, Trivers KF, Porter PL, Coates RJ, Leyland-Jones B, Brawley OW et al (2009) Race and triple negative threats to breast cancer survival: a population-based study in Atlanta, GA. Breast Cancer Res Treat 113(2):357-370

11. Stark A, Kleer CG, Martin I, Awuah B, Nsiah-Asare A, Takyi V et al (2010) African ancestry and higher prevalence of triple- 
negative breast cancer: findings from an international study. Cancer 116(21):4926-4932

12. Bhikoo R, Srinivasa S, Yu TC, Moss D, Hill AG (2011) Systematic review of breast cancer biology in developing countries (part 1): Africa, the Middle East, Eastern Europe, Mexico, the Caribbean and South America. Cancers 3:2358-2381

13. Amirikia KC, Mills P, Bush J, Newman LA (2011) Higher population-based incidence rates of triple-negative breast cancer among young African-American women: implications for breast cancer screening recommendations. Cancer 117(12):2747-2753

14. Agboola AJ, Musa AA, Wanangwa N, Abdel-Fatah T, Nolan CC, Ayoade BA et al (2012) Molecular characteristics and prognostic features of breast cancer in Nigerian compared with UK women. Breast Cancer Res Treat 135(2):555-569

15. Amend K, Hicks D, Ambrosone CB (2006) Breast cancer in African-American women: differences in tumor biology from European-American women. Can Res 66(17):8327-8330

16. Boyle P (2012) Triple-negative breast cancer: epidemiological considerations and recommendations. Ann Oncol 23(Suppl 6):vi7-vi12

17. Dietze EC, Sistrunk C, Miranda-Carboni G, O'Regan R, Seewaldt VL (2015) Triple-negative breast cancer in AfricanAmerican women: disparities versus biology. Nat Rev Cancer 15(4):248-254

18. Bauer KR, Brown M, Cress RD, Parise CA, Caggiano V (2007) Descriptive analysis of estrogen receptor (ER)-negative, progesterone receptor (PR)-negative, and HER2-negative invasive breast cancer, the so-called triple-negative phenotype: a population-based study from the California cancer Registry. Cancer 109(9): 1721-1728

19. Jones J, Wang H, Karanam B, Theodore S, Dean-Colomb W, Welch DR et al (2014) Nuclear localization of Kaiso promotes the poorly differentiated phenotype and EMT in infiltrating ductal carcinomas. Clin Exp Metasis 31(5):497-510

20. Jones J, Wang H, Zhou J, Hardy S, Turner T, Austin D et al (2012) Nuclear kaiso indicates aggressive prostate cancers and promotes migration and invasiveness of prostate cancer cells. Am J Pathol 181(5):1836-1846

21. Daniel JM, Reynolds AB (1999) The catenin p120(ctn) interacts with Kaiso, a novel BTB/POZ domain zinc finger transcription factor. Mol Cell Biol 19(5):3614-3623

22. Kelly KF, Daniel JM (2006) POZ for effect-POZ-ZF transcription factors in cancer and development. Trends Cell Biol 16(11):578-587

23. Daniel JM, Spring CM, Crawford HC, Reynolds AB, Baig A (2002) The p120(ctn)-binding partner Kaiso is a bi-modal DNAbinding protein that recognizes both a sequence-specific consensus and methylated $\mathrm{CpG}$ dinucleotides. Nucleic Acids Res 30(13):2911-2919

24. Prokhortchouk A, Hendrich B, Jorgensen H, Ruzov A, Wilm M, Georgiev G et al (2001) The p120 catenin partner Kaiso is a DNA methylation-dependent transcriptional repressor. Genes Dev 15(13):1613-1618

25. Donaldson NS, Pierre CC, Anstey MI, Robinson SC, Weerawardane SM, Daniel JM (2012) Kaiso represses the cell cycle gene cyclin D1 via sequence-specific and methyl-CpG-dependent mechanisms. PLoS ONE 7(11):e50398

26. Daniel JM (2007) Dancing in and out of the nucleus: p120(ctn) and the transcription factor Kaiso. Biochim Biophys Acta 1773(1):59-68

27. Rodova M, Kelly KF, VanSaun M, Daniel JM, Werle MJ (2004) Regulation of the rapsyn promoter by kaiso and delta-catenin. Mol Cell Biol 24(16):7188-7196

28. Blattler A, Yao L, Wang Y, Ye Z, Jin VX, Farnham PJ (2013) ZBTB33 binds unmethylated regions of the genome associated with actively expressed genes. Epigenetics Chromatin 6(1):13
29. Musgrove EA, Caldon CE, Barraclough J, Stone A, Sutherland RL (2011) Cyclin D as a therapeutic target in cancer. Nat Rev Cancer 11(8):558-572

30. Adachi Y, Yamamoto H, Itoh F, Hinoda Y, Okada Y, Imai K (1999) Contribution of matrilysin (MMP-7) to the metastatic pathway of human colorectal cancers. Gut 45(2):252-258

31. Onder TT, Gupta PB, Mani SA, Yang J, Lander ES, Weinberg RA (2008) Loss of E-cadherin promotes metastasis via multiple downstream transcriptional pathways. Can Res 68(10):36453654

32. Pierre CC, Longo J, Mavor M, Milosavljevic SB, Chaudhary R, Gilbreath E et al (2015) Kaiso overexpression promotes intestinal inflammation and potentiates intestinal tumorigenesis in Apc(Min/+) mice. Biochim Biophys Acta 1852(9):1846-1855

33. Dai SD, Wang Y, Miao Y, Zhao Y, Zhang Y, Jiang GY et al (2009) Cytoplasmic Kaiso is associated with poor prognosis in non-small cell lung cancer. BMC Cancer 9:178

34. Jones J, Mukherjee A, Karanam B, Davis M, Jaynes J, Reams RR et al (2016) African Americans with pancreatic ductal adenocarcinoma exhibit gender differences in Kaiso expression. Cancer Lett 380(2):513-522

35. Bassey-Archibong BI, Kwiecien JM, Milosavljevic SB, Hallett RM, Rayner LG, Erb MJ et al (2016) Kaiso depletion attenuates transforming growth factor- $\beta$ signaling and metastatic activity of triple-negative breast cancer cells. Oncogenesis 5:e208

36. Prokhortchouk A, Sansom O, Selfridge J, Caballero IM, Salozhin S, Aithozhina D et al (2006) Kaiso-deficient mice show resistance to intestinal cancer. Mol Cell Biol 26(1):199-208

37. Lopes EC, Valls E, Figueroa ME, Mazur A, Meng FG, Chiosis G et al (2008) Kaiso contributes to DNA methylation-dependent silencing of tumor suppressor genes in colon cancer cell lines. Can Res 68(18):7258-7263

38. Vermeulen JF, van de Ven RA, Ercan C, van der Groep P, van der Wall E, Bult P et al (2012) Nuclear Kaiso expression is associated with high grade and triple-negative invasive breast cancer. PLoS ONE 7(5):e37864

39. Daniel JM, Ireton RC, Reynolds AB (2001) Monoclonal antibodies to Kaiso: a novel transcription factor and p120ctn-binding protein. Hybridoma 20(3):159-166

40. Chaudhary R, Pierre CC, Nanan K, Wojtal D, Morone S, Pinelli C et al (2013) The POZ-ZF transcription factor Kaiso (ZBTB33) induces inflammation and progenitor cell differentiation in the murine intestine. PLoS ONE 8(9):e74160

41. Tracing African roots; exploring the ethnic origins of the AfroDiaspora

42. Murray T, Beaty TH, Mathias RA, Rafaels N, Grant AV, Faruque MU et al (2010) African and non-African admixture components in African Americans and an African Caribbean population. Genet Epidemiol 34(6):561-568

43. Weigelt B, Peterse JL, van't Veer LJ (2005) Breast cancer metastasis: markers and models. Nat Rev Cancer 5(8):591-602

44. Huo D, Ikpatt F, Khramtsov A, Dangou JM, Nanda R, Dignam J et al (2009) Population differences in breast cancer: survey in indigenous African women reveals over-representation of triplenegative breast cancer. J Clin Oncol 27(27):4515-4521

45. Sawe RT, Kerper M, Badve S, Li J, Sandoval-Cooper M, Xie J et al (2016) Aggressive breast cancer in western Kenya has early onset, high proliferation, and immune cell infiltration. BMC Cancer 16:204

46. Adisa CA, Eleweke N, Alfred AA, Campbell MJ, Sharma R, Nseyo O et al (2012) Biology of breast cancer in Nigerian women: a pilot study. Ann Afr Med 11(3):169-175

47. Fraizer M (2005) Continuity and change in Caribbean immigration. People's World

48. Jackson FL (2008) Ancestral links of Chesapeake Bay region African Americans to specific Bight of Bonny (West Africa) 
microethnic groups and increased frequency of aggressive breast cancer in both regions. Am J Hum Biol 20(2):165-173

49. Bryc K, Auton A, Nelson MR, Oksenberg JR, Hauser SL, Williams $S$ et al (2010) Genome-wide patterns of population structure and admixture in West Africans and African Americans. Proc Natl Acad Sci USA 107(2):786-791

50. McCabe A, Dolled-Filhart M, Camp RL, Rimm DL (2005) Automated quantitative analysis (AQUA) of in situ protein expression, antibody concentration, and prognosis. J Natl Cancer Inst 97(24):1808-1815

51. Bassey-Archibong BI, Rayner LG, Hercules SM, Aarts CW, Dvorkin-Gheva A, Bramson JL et al (2017) Kaiso depletion attenuates the growth and survival of triple negative breast cancer cells. Cell Death Dis 8(3):e2689 